\title{
Concentrations and gas-particle partitioning of PCDD/Fs in the urban air of Dalian, China
}

\author{
QIN SongTao ${ }^{1}$, ZHU XiuHua $^{1 *}$, WANG Wei ${ }^{1}$, CHEN JiPing $^{2}$, NI YuWen ${ }^{2}$, LI XiaoXiao ${ }^{3}$, \\ MU Jun ${ }^{1}$, XU Qian ${ }^{1} \&$ SCHRAMM Karl-Werner ${ }^{4}$ \\ ${ }^{1}$ School of Environmental and Chemical Engineering, Dalian Jiaotong University, Dalian 116028, China; \\ ${ }^{2}$ Dalian Institute of Chemical Physics, Chinese Academy of Sciences, Dalian 116023, China; \\ ${ }^{3}$ Dalian Meteorological Observatory, Dalian 116001, China; \\ ${ }^{4}$ Helmholtz Center Munich-German Research Center for Environmental Health, Molecular EXposomics (MEX), Ingolstädter Landstr. 1, 85764 \\ Neuherberg, Germany
}

Received December 25, 2011; accepted February 7, 2012; published online August 8, 2012

\begin{abstract}
PCDD/Fs in the urban air of Dalian, China were monitored with high-volume active sampler from November 2009 to October 2010. The concentration of $\mathrm{Cl}_{4-8} \mathrm{DD} / \mathrm{Fs}$ ranged from 3065 to $49538 \mathrm{fg} \mathrm{m}^{-3}$, with an average of $10249 \mathrm{fg} \mathrm{m}^{-3}$. The international toxic equivalents (I-TEQ) value of that was $61.8-1182 \mathrm{fg} \mathrm{m}^{-3}$, with an average of $235 \mathrm{fg} \mathrm{m}^{-3}$, which was comparable to those in the other urban locations around the world. It was found that the $\mathrm{Cl}_{4-8} \mathrm{DD} / \mathrm{Fs}$ appeared to be present mainly in the particle phase during winter, spring and autumn, while during summer which were dominantly in gas phase. The ratio of $\mathrm{Cl}_{4-8} \mathrm{DD} / \mathrm{Fs}$ present in particle phase increased with the increasing level of chlorination. The concentrations of PCDFs and PCDDs decreased with the increase of chlorinated level, while the concentrations of 2,3,7,8-PCDDs congeners increased with the increase of chlorination level. The homolog profiles of the concentrations of PCDFs presented were higher than those of the PCDDs, which indicated the PCDD/Fs pollution source of the air in Dalian was characteristic for thermal source pollution. The correlation analysis of meteorological parameters with the concentrations of $\mathrm{Cl}_{4-8} \mathrm{CDD} / \mathrm{Fs}$ was conducted using SPSS packages, and it was found that the ambient temperature and atmospheric pressure were important factors influence the concentration of PCDD/Fs in the air. The respiratory risk and intake dioxins of the residents around the sampling sites were studied in the paper. It was found that Junge-Pankow model was much more accurate in predicting the gas-particle partitioning behavior of PCDD/Fs homologues during winter, while the Harner-Bidleman model shows better agreement with the measured data during winter and summer.
\end{abstract}

PCDD/Fs, urban air, gas-particle partitioning, Dalian

Citation: $\quad$ Qin S T, Zhu X H, Wang W, et al. Concentrations and gas-particle partitioning of PCDD/Fs in the urban air of Dalian, China. Chin Sci Bull, 2012, 57: 3442-3451, doi: 10.1007/s11434-012-5320-y

Polychlorinated dibenzo- $p$-dioxins (PCDDs), polychlorinated dibenzofurans (PCDFs) are two species of persistent organic pollutants (POPs) in the environment. PCDD/Fs have received considerable public and scientific attention because of the acute toxicity of 2,3,7,8-tetrachlorodibenzo$p$-dioxin (2,3,7,8-TCDD) [1]. Due to their persistence and semivolatility, they can be transported over long distance on a global scale. Atmospheric transport is a primary pathway

*Corresponding author (email: zhuxiuhua1@ hotmail.com) for the transfer of semivolatile organic compounds (SVOCs) to the terrestrial and aquatic ecosystems via deposition [2,3]. A key process in determining the environmental fate of organic chemicals in the atmosphere is their partitioning between particle and gas phase. Wet and dry deposition, photolysis, and reaction with $\mathrm{OH}$ radicals act differently on gasand particle-bound SVOCs, thereby affecting the efficiency and scope of their long-range atmospheric transport. Meanwhile, the gas-particle partitioning also influences the degradation processes, chemical reactions, and long-range 
transport, and human and ecosystem health effects of atmospheric SVOCs [4-6]. At present, there are two main sorption models which have been used to describe gas/particle partitioning of PCDD/Fs, i.e. the Junge-Pankow model, adsorption to the particle surface using the subcooled liquid vapor pressure of the compounds $\left(P_{\mathrm{L}}^{0}\right)[7,8]$ and the HarnerBidleman model, absorption to the organic phase of aerosols using the octanol-air partition coefficient $\left(K_{\mathrm{oa}}\right)$ [9]. Absorptive partitioning is believed to be the dominant mechanism when an organic fraction exists on the aerosol [10,11].

Despite the recent efforts to investigate the occurrences of PCDD/Fs in the regional environment in China, including water, soil, sediments and pine (Cedrus deodara) needles [12-17], very little was known about the levels of $\mathrm{PCDD} / \mathrm{Fs}$ in the regional atmospheric environment in China [3,18-20], except those in Hong Kong and Taiwan [21,22] (http://www.epd-asg.gov.hk/english/report/dioxin.php).

Dalian $\left(120^{\circ} 58^{\prime}-123^{\circ} 31^{\prime} \mathrm{E}, 38^{\circ} 43^{\prime}-40^{\circ} 10^{\prime} \mathrm{N}\right)$ is a seaside city located on the southern tip of the Eastern Liaoning Peninsula of the northeast of China. Dalian, a typical metropolis of China, has a population of over six millions. The area of Dalian is $12574 \mathrm{~km}^{2}$ and its urban area is $2415 \mathrm{~km}^{2}$. Petrochemical industry, modern equipment manufacturing, ship building, electronic information industry are the four pillar industries of Dalian. Although, Dalian is one of the most livable cities in China, there are also some kinds of dispersed sources to produce PCDD/Fs that affect the air quality, such as motor vehicle exhausts, industrial emissions, winter heating, etc. To our knowledge, monitoring of PCDD/ Fs of the urban air of Dalian for the whole year has not been investigated so far [20].

The objectives of this study were to measure the concentrations of PCDD/Fs in the urban air of Dalian, to investigate the gas-particle distribution of PCDD/Fs in the air and the relations of which with the meteorological parameters, and to evaluate the exposure risk of the local residents in the pollutant air. Furthermore, the relative performances of Junge-Pankow and Harner-Bidleman models in evaluating the gas-particle partitioning behavior of PCDD/Fs during the four seasons were assessed.

\section{Materials and methods}

\subsection{Sampling}

The sampling process was conducted according to US EPA compendium method TO 9A. From November 2009 to October 2010 (except February 2010, the Chinese Spring Festival holiday), active high-volume air samplings (ECHO HiVol, TCR TECORA, Italy) were carried out at two sites in Dalian, China, which were selected based on their different surrounding environments, populations and traffic densities. The sampling sites were the rooftops of the No.1 building at Dalian Jiaotong University (DJU: $121^{\circ} 54.399^{\prime} \mathrm{E}$, $38^{\circ} 34.286^{\prime} \mathrm{N}$, elevation $32 \mathrm{~m}$ ) and the building of Dalian Meteorological Observatory (DMO: $121^{\circ} 38.730^{\prime} \mathrm{E}, 38^{\circ}$ 54.174 'N, elevation $113 \mathrm{~m}$ ).

DMO is located at a hillside. Surroundings of this site include residential buildings, university campus, a road with light traffic (Jiefang road is about $0.27 \mathrm{~km}$ from DMO) and a vast expanse of mountain, on which there are many trees and plants. The site is not far from Dalian port (DLP), which is about $3 \mathrm{~km}$ from DMO. DLP is a world-known deep and ice-free harbor, having shipping relations with over 160 countries and regions and undertaking more than $70 \%$ of cargo transportation. Dalian Newport (DNP) is a modern deepwater oil port, which is about $24 \mathrm{~km}$ from DMO.

DJU is located in the campus of Dalian Jiaotong University which is close to the residential buildings, research institutes, university's restaurants, barbecue stall street and adjacent to two roads with heavy traffic (Xinan road and Huanghe road are about 0.12 and $0.09 \mathrm{~km}$ from the DJU sampling site, respectively). In the campus of Dalian Jiaotong University there is a coal-fired boiler house, the chimney of that is about $0.12 \mathrm{~km}$ from DJU sampling site. A coal-fired power plant at the southwest of DJU is about 1.08 $\mathrm{km}$ form the sampling site. DJU is about $8.2 \mathrm{~km}$ from DLP and about $29.9 \mathrm{~km}$ from DNP.

The distance between DJU and DMO is about $6.45 \mathrm{~km}$. All sampling sites are located in open areas, without trees, buildings or any other sheltering objects near them.

Approximately $600 \mathrm{~m}^{3}$ air was collected per sample. Particle fraction was collected by a glass microfiber filter (GFF) (Whatman grade GF/A $110 \mathrm{~mm}$ diameter) and gas phase was collected by polyurethane foam (PUF) plug (length $76 \mathrm{~mm}$, diameter $63 \mathrm{~mm}$, density $0.0213 \mathrm{~g} \mathrm{~m}^{-3}$ ). The preconditioning of GFF and PUF were performed as described by Wang et al. [20]. Air volume recorded by the sampler was used to calculate the concentrations of PCDD/Fs. Background contamination was monitored by using operational field blanks (unexposed filter and PUF) which were processed simultaneously with the samples.

\subsection{Meteorological conditions and the unit of $P_{\mathrm{L}}^{0}$}

Dalian Meteorological Observatory provided meteorological data synchronously with the sampling period. The parameters included average temperature $(T)$, average pressure $(P)$, average relative humidity $(\mathrm{RH})$, average wind speed (WS) and the total suspended particles (TSP). The meteorological data and TSP values are listed in Table 1.

A previous study indicated that the estimation of subcooled liquid vapor pressure of the compounds, $P_{\mathrm{L}}^{0}$ by using Mader and Pankow method [23] could give the best fitting performance [24]. In this paper, $P_{\mathrm{L}}^{0}(\mathrm{~Pa})$ was also estimated based on Mader and Pankow method using the average 
Table 1 Meteorology parameters and TSP values during sampling periods

\begin{tabular}{|c|c|c|c|c|c|}
\hline Data & $P$ (hpa) & $T\left({ }^{\circ} \mathrm{C}\right)$ & RH (\%) & WS $\left(\mathrm{m} \mathrm{s}^{-1}\right)$ & $\mathrm{TSP}\left(\mu \mathrm{g} \mathrm{m}^{-3}\right)$ \\
\hline Nov. 2009 & 1013.9 & 1.0 & 75.3 & 3.7 & 96.7 \\
\hline Dec. 2009 & 1015.7 & -4.5 & 54.5 & 3.4 & 128.4 \\
\hline Jan. 2010 & 1018.2 & -6.2 & 68.3 & 2.5 & 64.9 \\
\hline Mar. 2010 & 1003.2 & 2.2 & 63.0 & 4.1 & 82.9 \\
\hline Apr. 2010 & 1006.8 & 7.8 & 61.2 & 2.8 & 65.0 \\
\hline May 2010 & 1000.1 & 16.3 & 62.3 & 3.7 & 92.6 \\
\hline Jun. 2010 & 994.7 & 20.7 & 69.0 & 3.9 & 51.3 \\
\hline Jul. 2010 & 997.3 & 23.1 & 92.0 & 3.6 & 64.3 \\
\hline Aug. 2010 & 1001.8 & 25.0 & 85.5 & 3.1 & 103.6 \\
\hline Sept. 2010 & 1003.7 & 20.2 & 71.5 & 2.7 & 91.0 \\
\hline Oct. 2010 & 1007.9 & 13.3 & 78.8 & 3.9 & 70.4 \\
\hline
\end{tabular}

ambient temperatures.

\subsection{Sample extraction and analysis}

The samples were prepared according to the US EPA method 1613. All ${ }^{13} \mathrm{C}_{12}$-labeled PCDD/Fs standards were obtained from Cambridge Isotope Laboratories Inc. USA (purities $>98 \%$ ). In general, the solvents and reagents used for the study were all pesticide or higher grade.

The extraction, cleanup and analysis of the sample were performed as described by Wang et al. [20]. International toxic equivalents (I-TEQ) values were calculated by using international toxicity equivalency factor (I-TEF).

\subsection{Quality assurance and quality control}

All of the samples were spiked with labeled compounds to monitor the clean performance of the method. Field and laboratory blank were incorporated in the analytical procedure. There were no apparent differences between field blanks and laboratory blanks. The recoveries for ${ }^{13} \mathrm{C}-\mathrm{OCDD}$ were 34\%-92\%. The recoveries for other ${ }^{13} \mathrm{C}$ labeled PCDD/ Fs were $42 \%-136 \%$. All the sample recoveries met the limits of US EPA method 1613. The detection limits were defined as three times of signal/noise ratio.

\section{Results and discussion}

\subsection{PCDD/Fs levels in the ambient air}

Total 37-128 and 81-129 congeners of PCDD/Fs were detected in gas phase (PUF) and particle phase (GFF) at DJU, respectively. A total of 41-124 and 79-128 congeners of $\mathrm{PCDD} / \mathrm{Fs}$ were detected in PUF and GFF at DMO, respectively. The total concentrations of 303-3823 and 1028$48617 \mathrm{fg} \mathrm{m}^{-3}$ PCDD/Fs were detected in PUF and GFF at DJU, respectively. The total concentrations of 459-4625 and 524-14878 $\mathrm{fg} \mathrm{m}^{-3}$ PCDD/Fs were detected in PUF and GFF at DMO, respectively. The concentrations and I-TEQs of the seventeen most toxic 2,3,7,8-substituted PCDD/Fs at DJU and DMO in the air of Dalian are listed in Table S1. The total concentrations (PUF+GFF) of $\sum \mathrm{Cl}_{4-8} \mathrm{CDD} / \mathrm{Fs}$ in the air are also listed in Table S1. Figure 1 is the contributions of different congeners to the total concentrations of $\sum \mathrm{Cl}_{4-8} \mathrm{CDD} / \mathrm{Fs}$ at the two sampling sites. It shows that the dominant contributors were the $\sum \mathrm{TCDF}-\sum \mathrm{HxCDF}$. Lohmann et al. [25] indicated that homologue group profiles taken in coastal areas showed similar profiles; namely, generally decreasing concentrations for the PCDFs with the increasing degree of chlorination and increasing concentrations for the PCDDs with increasing chlorination level. Figure 1 shows that the concentrations of PCDFs decreased with the increase of chlorinated level, which was consistent with the results of Lohmann et al. [25]. While, with increasing level of chlorination of the PCDDs, the concentrations of PCDDs decreased also, this was contrary to the previous results [25]. However, it was found interestingly that the concentrations (PUF+GFF) of 2,3,7,8-PCDDs congeners increased with the increase of chlorination level (Figure 2). During the whole monitoring campaigns, it was found that the concentrations of $\sum$ PDCC/Fs was higher in winter (23377 $\mathrm{fg} \mathrm{m}^{-3}$ )(Dec., 2009-Jan., 2010) and autumn $\left(10358 \mathrm{fg} \mathrm{m}^{-3}\right.$ ) (Sep., 2010; Oct., 2010; Nov., 2009), lower in summer (3944 $\mathrm{fg} \mathrm{m}^{-3}$ ) (June, 2010-Aug., 2010) and spring (7694 $\mathrm{fg} \mathrm{m}^{-3}$ ) (Mar., 2010-May, 2010), which was consistent with previous studies [3,26].

Figure 1 shows that the homologue profiles presented higher concentrations of PCDFs compared with PCDDs. Table $\mathrm{S} 1$ shows that the ratio of $\sum \mathrm{Cl}_{4-8} \mathrm{CDDs}$ to $\sum \mathrm{Cl}_{4-8^{-}}$ CDFs was 0.2-0.6, which was lower than 1 . It means that the PCDD/Fs pollution source was not far away and was characteristic for thermal source pollution [7,17,18,27]. The congener profiles for the two sampling sites were similar (Figures 1 and 2, Table S1), indicating that they came from 


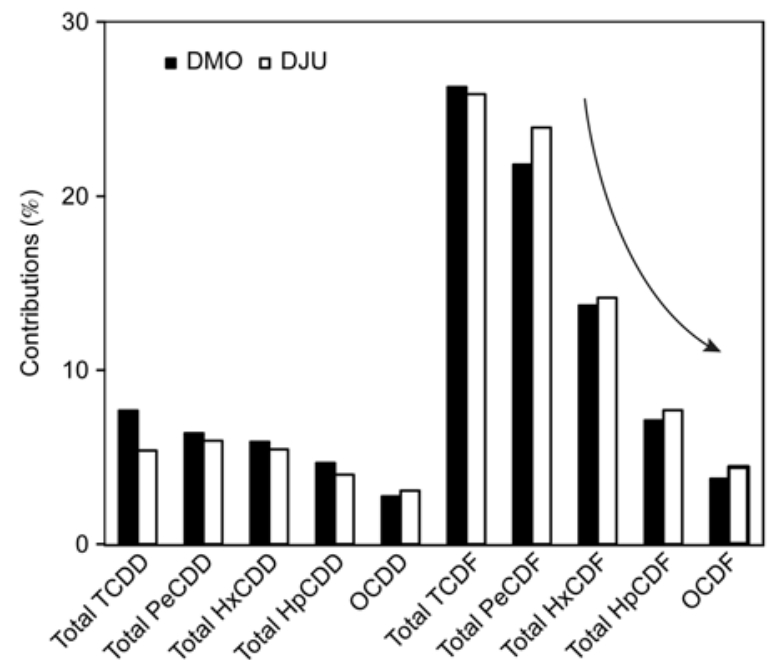

Figure 1 Relative average abundance of PCDD/Fs homologues to the total concentrations.

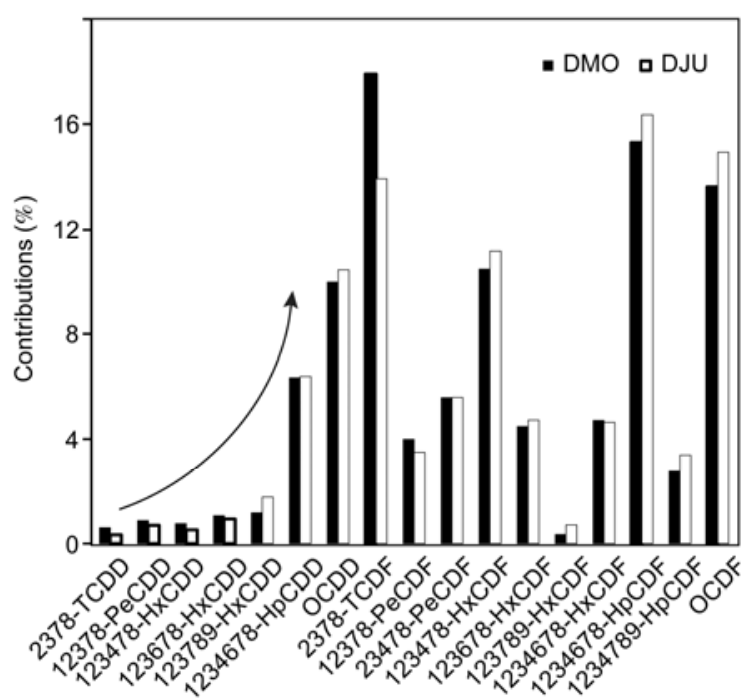

Figure 2 Relative abundance of $2,3,7,8-\mathrm{PCDD} / \mathrm{Fs}$ congeners to the total concentrations.

similar pollution sources. Niu et al. [28] found that combusting wood, polyvinyl chloride, high-density polyethylene, and styrene produced the amounts of PCDFs were also higher than PCDDs. Surrounding the two sampling sites, there are heavy traffics, residential buildings, coal burning boiler house. Therefore, PCDD/Fs at Dalian may mainly come from various combustion processes for thermoelectricity, domestic heating, and vehicle emissions. Indeed, no significant point sources of PCDD/Fs in urban Dalian can be identified [17]. However, the other anthropogenic activities and long-distance air-transportation from other places might contribute to dioxin pollution of Dalian, too.

$2,3,4,7,8-\mathrm{PeCDF}$ contributed dominantly to the total I-TEQ value, which was consistent with the results of urban emissions from combustion [2,29,30], the monthly average contribution of that to the total I-TEQs was $35 \%$. Other important contributors were 2,3,7,8-TCDF, 1,2,3,4,7,8-HxCDF, $1,2,3,6,7,8-\mathrm{HxCDF}$ and $2,3,4,6,7,8-\mathrm{HxCDF}$ with the monthly average contribution rates of $19 \%, 13 \%, 6 \%$ and $5 \%$, respectively.

According to the I-TEQ value in Table S1, it can be found that the air quality around DMO (annual average value: $183 \mathrm{fg}$ I-TEQ $\mathrm{m}^{-3}$ ) was better than that of DJU (annual average value: $284 \mathrm{fg}^{\mathrm{I}-T E Q ~ \mathrm{~m}^{-3}}$ ). In comparison with the PCDD/Fs standard of $1000 \mathrm{fg}^{\mathrm{I}-T E Q ~ \mathrm{~m}^{-3}}$ expressed as 2,3,7,8-TCDD equivalent in the ambient State of Connecticut in USA (USA EPA, 1991) [18] and the ambient air standard of $600 \mathrm{fg}^{\mathrm{I}-T E Q ~ \mathrm{~m}^{-3}}$ in Japan [3], the I-TEQ value is lower in Dalian atmosphere, indicating that the atmosphere quality in Dalian was better.

Table S2 is the comparison of ambient air I-TEQs of PCDD/Fs in Dalian with the other cities in the world. Its I-TEQ level was comparable to the other urban sites around the world. With regard to the domestic investigations, the average I-TEQs of PCDD/Fs level in the air of Dalian (I-TEQ $235 \mathrm{fg} \mathrm{m}^{-3}$ ) was lower than those of Beijing (I-TEQ $268 \mathrm{fg} \mathrm{m}^{-3}$ ) [3], Guangzhou (In particle phase, Liwan, I-TEQ $430.5 \mathrm{fg} \mathrm{m}^{-3}$; Huangpu, I-TEQ $769.3 \mathrm{fg} \mathrm{m}^{-3}$ ) [18], and Shanghai (Jiading District, I-TEQ $497.1 \mathrm{fg} \mathrm{m}^{-3}$; Zhabei District, I-TEQ $289.0 \mathrm{fg} \mathrm{m}^{-3}$ ) [19].

\subsection{Partitioning of $\mathrm{Cl}_{4-8} \mathrm{DD} / \mathrm{Fs}$ between gas and particle phase}

No matter in gas phase or in particle phase, the monthly average concentration variation of $\mathrm{Cl}_{4-8} \mathrm{DD} / \mathrm{Fs}$ homologues at the two sampling sites were similar (Figures 1 and 2, Table S1) and when all data of gas phase or particle phase samples at DJU and DMO were compared by the $t$-test, the concentration of $\mathrm{Cl}_{4-8} \mathrm{DD} / \mathrm{Fs}$ at the two sampling sites were not significantly different $(P>0.05)$, so the average concentration of $\mathrm{Cl}_{4-8} \mathrm{DD} / \mathrm{Fs}$ at the two sampling sites was used in the following discussion.

The relative gas-particle partition of $\mathrm{Cl}_{4-8} \mathrm{DD} / \mathrm{Fs}$ homologues in different seasons is shown in Figure 3. During winter, the $\mathrm{Cl}_{4-8} \mathrm{DD} / \mathrm{Fs}$ appeared to be present mainly in the particle phase, with an average contribution of $97.1 \%$ to the total concentrations, but the average contribution of $\mathrm{Cl}_{4-8} \mathrm{DD} /$ Fs in particle phase was $38.7 \%$ to the total concentrations in summer. During spring and autumn, the distributions were similar, $\mathrm{Cl}_{4-8} \mathrm{DD} / \mathrm{Fs}$ were $69.3 \%$ and $78.3 \%$ in the particle phase, respectively. During four seasons, the total TCDDs and total TCDFs in particle phase ranged from $7.2 \%$ to $93.7 \%$ and from $13.1 \%$ to $93.0 \%$, respectively. $\mathrm{Cl}_{5-7} \mathrm{DD} / \mathrm{Fs}$ and OCDD bound to the particle phase in spring, summer and autumn were $72.2 \%-89.7 \%, 23.7 \%-88.5 \%, 77.1 \%-$ $97.5 \%$, respectively. Very small amounts of $\mathrm{Cl}_{5-7} \mathrm{DD} / \mathrm{Fs}$ and OCDD were detected in gas phase during winter. OCDF was found only in the particle phase during spring and winter. 

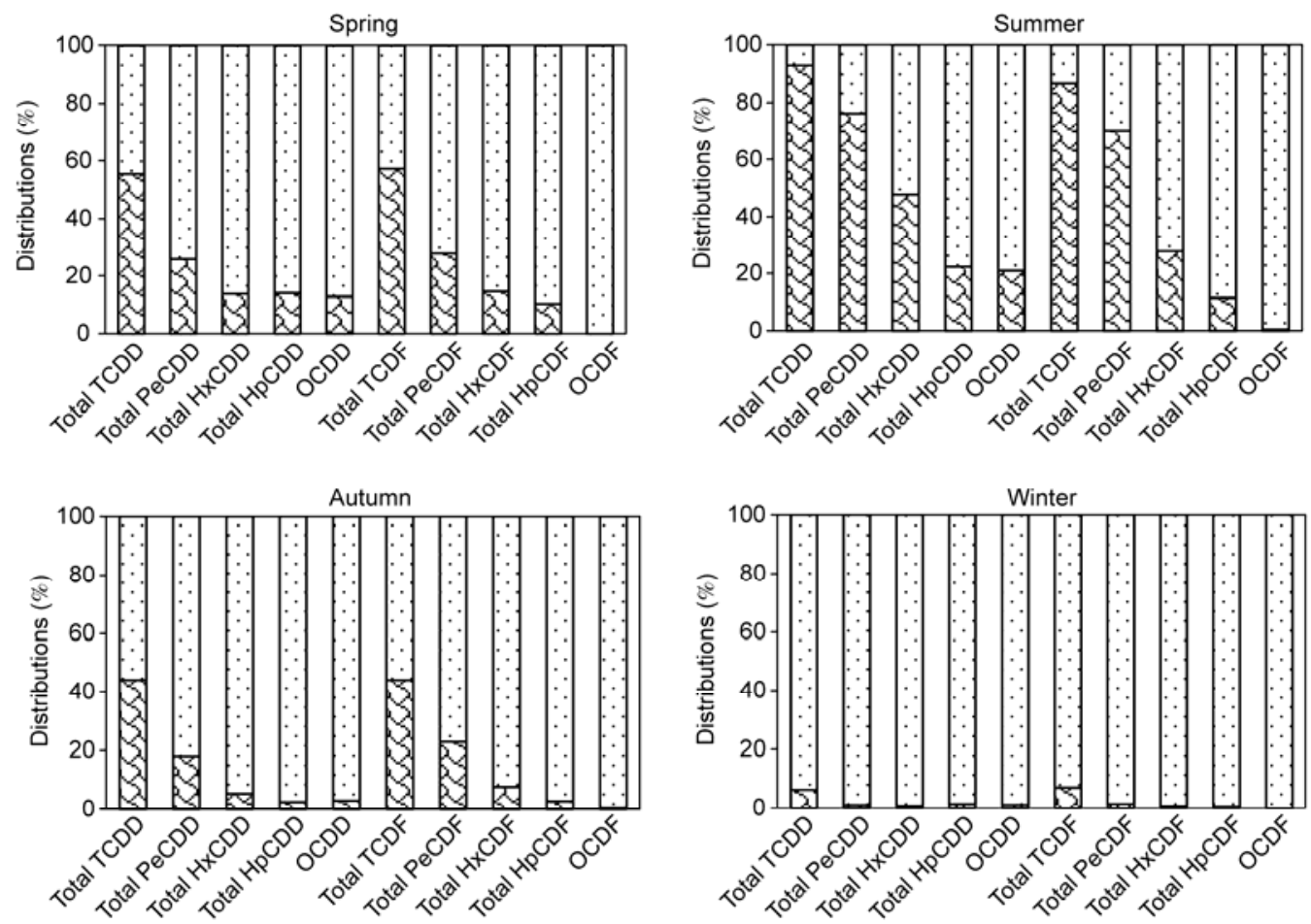

Figure 3 Relative distributions of PCDD/Fs between gas phase and particle phase in the air of Dalian. $\square$ GFF, ${ }^{\circ}$ PUF.

The ratio of $\mathrm{Cl}_{4-8} \mathrm{DD} / \mathrm{Fs}$ contained in particle phase increased with the increase of chlorinated level, which is consistent with the results of the ambient air of Houston [29].

Ambient temperature has much more effect on the gas-particle distribution of the $\mathrm{Cl}_{4 / 5} \mathrm{DD} / \mathrm{Fs}$. In this study the particle-bound $\mathrm{Cl}_{4 / 5} \mathrm{DD} / \mathrm{Fs}$ were $>90 \%$ in winter samples, but generally $<15 \%$ in summer samples, which were similar with the results of Lohmann et al. [31]. On the contrary, OCDF was not sensitive to the temperature, it was almost presented in particle phase all over the year (only 3.5\% and $0.5 \%$ in gas phase in summer and autumn samples, respectively). Moreover, the mean temperature during the autumn $\left(11.1^{\circ} \mathrm{C}\right)$ was higher than that during the spring $\left(8.7^{\circ} \mathrm{C}\right)$, but the ratio of the gas to particle phase distribution of $\mathrm{Cl}_{4-8} \mathrm{DD} / \mathrm{Fs}$ in spring was larger than that in autumn. This means that the gas-particle partitioning of $\mathrm{Cl}_{4-8} \mathrm{DD} / \mathrm{Fs}$ was not only influenced by ambient temperature, but also by the air pressure, wind speed, humidity, TSP, etc.

The correlation analysis of meteorological parameters with the concentrations of $\mathrm{Cl}_{4-8} \mathrm{CDD} / \mathrm{Fs}$ was conducted using SPSS packages. The Spearman rank correlation coefficients are listed in Table S3. Table S3 shows that the concentrations of $\sum 2378-\mathrm{PCDD} / \mathrm{Fs}$ and $\sum \mathrm{Cl}_{4-8} \mathrm{DD} / \mathrm{Fs}$ in PUF with air pressure and temperature had much higher negative $(-0.654 *,-0.601)$ and positive correlations $(0.761 * *, 0.734 *)$ than the other meteorological parameters, respectively. In contrast, those in GFF were correlated positively with air pressure $\left(0.901 * *, 0.895^{* *}\right)$, negatively with temperature $(-0.898 * *,-0.884 * *)$, respectively. This means that the concentrations of PCDD/Fs in PUF decreased with the in- crease of atmospheric pressure, and increased with the increase of temperature, but those in GFF displayed a reverse trend. The $\sum \mathrm{Cl}_{4-8} \mathrm{DD} / \mathrm{Fs}$ in PUF and GFF had little correlation with TSP, relative humidity and wind speed. Lee et al. [32] also found no obvious differences in the levels of PCDD/Fs during the dust events despite the very large increase in particulate matter in southeastern Korea. But roughly, the concentrations of $\sum 2378-\mathrm{PCDD} / \mathrm{Fs}$ and $\sum \mathrm{Cl}_{4-8} \mathrm{DD} / \mathrm{Fs}$ in PUF were positively correlated with the relative humidity of the air and negative correlation with TSP, however, which in GFF displayed just a reverse trend. In addition the concentrations of PCDD/Fs show a few negative correlations with wind speed.

\section{3 $\log K_{\mathrm{p}}$ versus $\log P_{\mathrm{L}}^{0}$ correlations}

The gas-particle partitioning behavior of SVOCs is commonly described with the gas-particle partition coefficient $K_{\mathrm{p}}\left(\mathrm{m}^{3} \mu \mathrm{g}^{-1}\right)$, which can be calculated according to the following equation:

$$
K_{\mathrm{p}}=\frac{F / \mathrm{TSP}}{A},
$$

where $F$ and $A$ are the analytical concentrations of SVOCs in GFF and PUF samples, respectively, and TSP is the total suspended particulate matters $\left(\mu \mathrm{g} \mathrm{m}^{-3}\right)$. Only the detected data of the analyst above the detection limits in both phases were included in the calculation. When $\log K_{\mathrm{p}}$ is regressed against the $T$-corrected ( $T$ is the ambient temperature, the unit of which is $\mathrm{K}$.) $\log P_{\mathrm{L}}^{0}$ of the compound, useful information 
about the partitioning can be extracted from the slope, $m_{r}$, and the intercept, $b_{\mathrm{r}}$, of the tendency line [33]:

$$
\log K_{\mathrm{p}}=m_{r} \log P_{\mathrm{L}}^{0}+b_{r} .
$$

For equilibrium partitioning of the chemicals between the gas and particle phases, the slope $m_{\mathrm{r}}$ for either adsorption or absorption should be close to -1 [34]. However, Goss and Schwarzenbach [11] and Simcik et al. [35] argued that a slope value of -1 in the regression of $\log K_{\mathrm{p}}$ versus $\log P_{\mathrm{L}}^{0}$ is not necessary to describe equilibrium partitioning. Slopes significantly steeper than -1 indicate adsorption while slopes shallower than -0.6 point to absorption, slops in the range between -0.6 and -1 can occur for absorption as well as for adsorption [11]. The intercept $b_{\mathrm{r}}$ is dependent on the type and properties associated with the aerosol.

Table 2 shows the regression of $\log K_{\mathrm{p}}$ versus $\log P_{\mathrm{L}}^{0}$ at the two sampling sites during the whole year and in the four seasons, respectively. Significant linear correlations are observed between the regressions of the $\log K_{\mathrm{p}}$ versus $\log P_{\mathrm{L}}^{0}$. From Table 2, it can be seen that the slope values were $>-1$, indicating that PCDD/Fs did not approach equilibrium between the particle and gas phases. The gas-particle partitioning of PCDD/Fs appeared to be more close to equilibrium at the two sampling sites in spring and summer than in the other seasons. The slope values were mainly between -0.6 and -1 in this study, indicating that both the absorption and adsorption mechanisms contributed to the partitioning process [3,11]. The $m_{\mathrm{r}}$ and $b_{\mathrm{r}}$ at both sampling sites for the whole year were similar, but they were different at the same sampling site in the four seasons. Xu et al. [24] also found that $m_{\mathrm{r}}$ and $b_{\mathrm{r}}$ showed large variations from location to location and event to event.

\subsection{Inhalation risk assessment of dioxins in the air for the local residents}

Human suffered potentially exposure to dioxins in the environment through a variety of pathways, in which inhalation was considered as an important way of exposure. It is assumed that individual was exposed to contaminated air 24 $\mathrm{h} \mathrm{d}^{-1}$. The daily inhalation dose of dioxin for adults/children is calculated as follows [36]:

$$
I P_{\text {ad } / \mathrm{ch}}=V r_{\text {ad } / \mathrm{ch}} \cdot C_{\text {air }} \cdot f_{\mathrm{r}} \cdot t_{\mathrm{f}} / W,
$$

where $I P_{\text {ad/ch }}$ is inhalation exposure in pg TEQ $\mathrm{kg}^{-1} \mathrm{~d}^{-1}$ for adults/children. $V r_{\text {ad/ch }}$ is ventilation rate for adults $20 \mathrm{~m}^{3} \mathrm{~d}^{-1}$ and for children $7.6 \mathrm{~m}^{3} \mathrm{~d}^{-1}$, and $C_{\text {air }}\left(\mathrm{pg}\right.$ I-TEQ $\left.\mathrm{m}^{-3}\right)$ is the average TEQs of PCDD/Fs (PUF+GFF). The alveolar fraction retained in the lungs, $f_{\mathrm{r}}$ is 0.75 . The $t_{\mathrm{f}}$ is time fraction that adults (0.62)/children (0.45) spend at the impact site. $W$ is body weight for adult $70 \mathrm{~kg}$ and child $15 \mathrm{~kg}$ [36].

Table 3 shows the rough amounts of dioxin intake through breathing for Dalian residents around DJU and DMO sampling sites in the four seasons. The results show that the annual average respiratory risk (adults: $3.82 \times 10^{-2}$ pg I-TEQ $\mathrm{kg}^{-1} \mathrm{~d}^{-1}$; children: $4.93 \times 10^{-2}$ pg I-TEQ $\mathrm{kg}^{-1} \mathrm{~d}^{-1}$ ) of the residents around DJU was higher than the residents surrounding DMO (adults: $2.43 \times 10^{-2}$ pg I-TEQ $\mathrm{kg}^{-1} \mathrm{~d}^{-1}$; children: $3.13 \times$ $10^{-2} \mathrm{pg}$ I-TEQ $\mathrm{kg}^{-1} \mathrm{~d}^{-1}$ ). Especially in winter, the risk of dioxin inhalation by residents around DJU was twice more than that of DMO's. The strong wind blowing from the sea provided good air dispersion for DMO district, but for DJU district, dense combustion sources and population, heavy traffic and poor mixing of air resulted in lower air quality. In addition, Table 3 shows that the inhalation exposure values of children were larger than adults. It means that inhalation of the same dose of dioxins of the air resulted more negative impact on children than on adults.

Due to the lack of other intake data (such as diet and skin contact, etc.), the total daily intake of dioxins of the residents of Dalian city could not be accurately calculated. In Japan, the respiratory intake amounts of dioxin accounted for $2.61 \%$ of the total daily intake (average value of three years 1999, 2001, 2003) (http://www.env.go.jp/en/topic/

\begin{tabular}{|c|c|c|c|c|c|c|}
\hline Sampling site & Parameters & Winter & Spring & Summer & Autumn & Whole year \\
\hline \multirow{5}{*}{ DJU } & $r^{2}$ & 0.61 & 0.85 & 0.77 & 0.94 & 0.89 \\
\hline & $n$ & 22 & 30 & 33 & 51 & 40 \\
\hline & $T_{\mathrm{m}}\left({ }^{\circ} \mathrm{C}\right)$ & -4.40 & 7.00 & 21.90 & 13.80 & 10.90 \\
\hline & $m_{\mathrm{r}}$ & -0.58 & -0.89 & -0.71 & -0.76 & -0.67 \\
\hline & $b_{\mathrm{r}}$ & -3.30 & -5.62 & -4.88 & -4.64 & -4.15 \\
\hline \multirow{5}{*}{ DMO } & $r^{2}$ & 0.85 & 0.82 & 0.87 & 0.88 & 0.82 \\
\hline & $n$ & 31 & 30 & 22 & 55 & 47 \\
\hline & $T_{\mathrm{m}}\left({ }^{\circ} \mathrm{C}\right)$ & -6.40 & 10.80 & 24.00 & 9.20 & 10.70 \\
\hline & $m_{\mathrm{r}}$ & -0.46 & -0.73 & -0.88 & -0.51 & -0.60 \\
\hline & $b_{\mathrm{r}}$ & -3.26 & -5.12 & -5.34 & -3.75 & -4.23 \\
\hline
\end{tabular}

Table 2 Correlations of $\log K_{\mathrm{p}}$ versus $\log P_{\mathrm{L}}^{0 \text { a) }}$

a) $r^{2}$ : correlation coefficient; $n$ : number of data. 
Table 3 Rough inhalation risk assessment for the two districts in Dalian, China

\begin{tabular}{|c|c|c|c|c|c|c|}
\hline \multirow{2}{*}{ Region } & \multirow{2}{*}{ Time } & \multirow{2}{*}{$\begin{array}{c}C_{\text {air(PUF+GFF) }} \\
\left(\text { pg I-TEQ m }{ }^{-3}\right)\end{array}$} & \multicolumn{2}{|c|}{$I P_{\text {ad/ch }}\left(p g\right.$ I-TEQ kg $\left.{ }^{-1} \mathrm{~d}^{-1}\right)$} & \multicolumn{2}{|c|}{ Total intake (pg I-TEQ $\mathrm{kg}^{-1} \mathrm{~d}^{-1}$ ) } \\
\hline & & & Adults & Children & Adults & Children \\
\hline \multirow{5}{*}{ DJU } & Spring & $13.47 \times 10^{-2}$ & $1.79 \times 10^{-2}$ & $2.30 \times 10^{-2}$ & 0.69 & 0.88 \\
\hline & Summer & $7.99 \times 10^{-2}$ & $1.06 \times 10^{-2}$ & $1.37 \times 10^{-2}$ & 0.41 & 0.52 \\
\hline & Autumn & $29.49 \times 10^{-2}$ & $3.92 \times 10^{-2}$ & $5.04 \times 10^{-2}$ & 1.50 & 1.93 \\
\hline & Winter & $82.05 \times 10^{-2}$ & $10.90 \times 10^{-2}$ & $14.03 \times 10^{-2}$ & 4.18 & 5.38 \\
\hline & Whole year & $28.81 \times 10^{-2}$ & $3.82 \times 10^{-2}$ & $4.93 \times 10^{-2}$ & 1.46 & 1.89 \\
\hline \multirow{5}{*}{ DMO } & Spring & $17.14 \times 10^{-2}$ & $2.28 \times 10^{-2}$ & $2.93 \times 10^{-2}$ & 0.87 & 1.12 \\
\hline & Summer & $7.33 \times 10^{-2}$ & $0.97 \times 10^{-2}$ & $1.25 \times 10^{-2}$ & 0.37 & 0.48 \\
\hline & Autumn & $19.49 \times 10^{-2}$ & $2.59 \times 10^{-2}$ & $3.33 \times 10^{-2}$ & 0.99 & 1.28 \\
\hline & Winter & $34.63 \times 10^{-2}$ & $4.60 \times 10^{-2}$ & $5.92 \times 10^{-2}$ & 1.76 & 2.27 \\
\hline & Whole year & $18.28 \times 10^{-2}$ & $2.43 \times 10^{-2}$ & $3.13 \times 10^{-2}$ & 0.93 & 1.20 \\
\hline
\end{tabular}

dioxins.html). China and Japan are neighboring countries, especially for Dalian which is only a short distance apart from Japan. It is assumed that the diets of Dalian and Japan residents are based on similar seafood. Therefore, the total intake dioxins by Dalian residents at the two sampling sites in the four seasons can be roughly calculated by multiplying $2.61 \%$ of the respiratory intake amounts of dioxin of the air. The results are listed in Table 3, too. The results showed that the annual average total daily intake (adults: $1.46 \mathrm{pg}$ I-TEQ $\mathrm{kg}^{-1} \mathrm{~d}^{-1}$; children: 1.89 pg I-TEQ $\mathrm{kg}^{-1} \mathrm{~d}^{-1}$ ) of the residents around DJU was higher than the residents' surrounding DMO (adults: 0.93 pg I-TEQ $\mathrm{kg}^{-1} \mathrm{~d}^{-1}$; children: $1.20 \mathrm{pg}$ I-TEQ $\mathrm{kg}^{-1} \mathrm{~d}^{-1}$ ) and Tianhe District of Guangzhou, China (adults: $1.1 \mathrm{pg}$ I-TEQ $\mathrm{kg}^{-1} \mathrm{~d}^{-1}$; children: $1.5 \mathrm{pg}$ I-TEQ $\mathrm{kg}^{-1} \mathrm{~d}^{-1}$ ), but was lower than Liwan District of Guangzhou (adults: 3.1 pg I-TEQ kg $\mathrm{kg}^{-1}$; children: $4.1 \mathrm{pg}$ I-TEQ $\mathrm{kg}^{-1} \mathrm{~d}^{-1}$ ) [37]. In winter, the total daily intake amounts of dioxins of the residents around DJU (adults: 4.18 pg I-TEQ kg ${ }^{-1} \mathrm{~d}^{-1}$; children: 5.38 pg I-TEQ $\mathrm{kg}^{-1} \mathrm{~d}^{-1}$ ) had exceeded the World Health Organization standards, acceptable daily intake of the body is $1-4$ pg I-TEQ kg ${ }^{-1} \mathrm{~d}^{-1}$ [38]. This means that the residents surrounding DJU had suffered some threat of dioxins.

\subsection{Gas/particle partitioning models}

(i) The application of Junge-Pankow model. Junge [7] and Pankow [8] based their partitioning model on the linear Langmuir sorption isotherm. It relates the particle-bound fraction of the chemicals, $\varphi$ with $P_{\mathrm{L}}^{0}$ of the compound and the particle surface area per volume of air $(\theta)$ :

$$
\varphi=\frac{c \theta}{P_{\mathrm{L}}^{0}+c \theta}
$$

where $c$ is a constant which depends on the heat of condensation of the chemical and surface properties. $\theta$ ranges from
$4.2 \times 10^{-5}$ for clean continental background, $1.5 \times 10^{-4}$ for rural area, and $1.1 \times 10^{-3} \mathrm{~m}^{2}$ aerosol $\mathrm{m}^{-3}$ for urban area. An empirical value of $c=0.172 \mathrm{~Pa} \mathrm{~m}$, as assumed by Junge [7] was employed in this study. The measured $\varphi$ was calculated using the ambient concentrations in the particle phase divided by the total ambient concentrations (PUF+GFF).

Figure 4 compares the particulate fractions $(\varphi)$ of PCDD/ Fs predicted by Junge-Pankow model with the measured data for each sampling event. Good agreement was obtained at the two sites between the predicted and measured $\varphi$ values in winter, in which the measured $\varphi$ values were close to the urban partitioning curve. However, during spring and summer, the model overestimated the particulate sorption of PCDD/Fs, which was consistence with Harner et al. [9] results. The predicted $\varphi$ values tends to be slightly underestimated for the lower chlorinated compounds $\left(\log P_{\mathrm{L}}^{0}>-4.0\right)$ and slightly overestimated for the higher chlorinated compounds during autumn at the two sampling sites. The deviation between the modeling and the measurement data may be due to the precision of $P_{\mathrm{L}}^{0}$ used in the model. In addition, the different aerosol types may cause significant fitting errors in the gas-particle partitioning of PCDD/Fs.

(ii) The application of Harner and Bidleman model. Finzio et al. [39] suggested that the octanol-air partition coefficient $\left(K_{\mathrm{oa}}\right)$ is an excellent descriptor for gas to aerosol partitioning. Harner and Bidleman [9] reproduced the work with $K_{\text {oa }}$ and the organic matter fraction $\left(f_{\text {om }}\right)$ of the aerosols:

$$
\log K_{\mathrm{P}}=\log K_{\text {oa }}+\log f_{\text {om }}-11.91 \text {. }
$$

The fraction on particles is then calculated from $K_{\mathrm{p}}$ and TSP by the following equation:

$$
\varphi=\frac{K_{\mathrm{p}} \mathrm{TSP}}{K_{\mathrm{p}} \mathrm{TSP}+1} .
$$

Harner et al. [40] derived a simple method for estimated $K_{\text {oa }}$ that correlates measured $K_{\mathrm{oa}}$ values against reported retention 

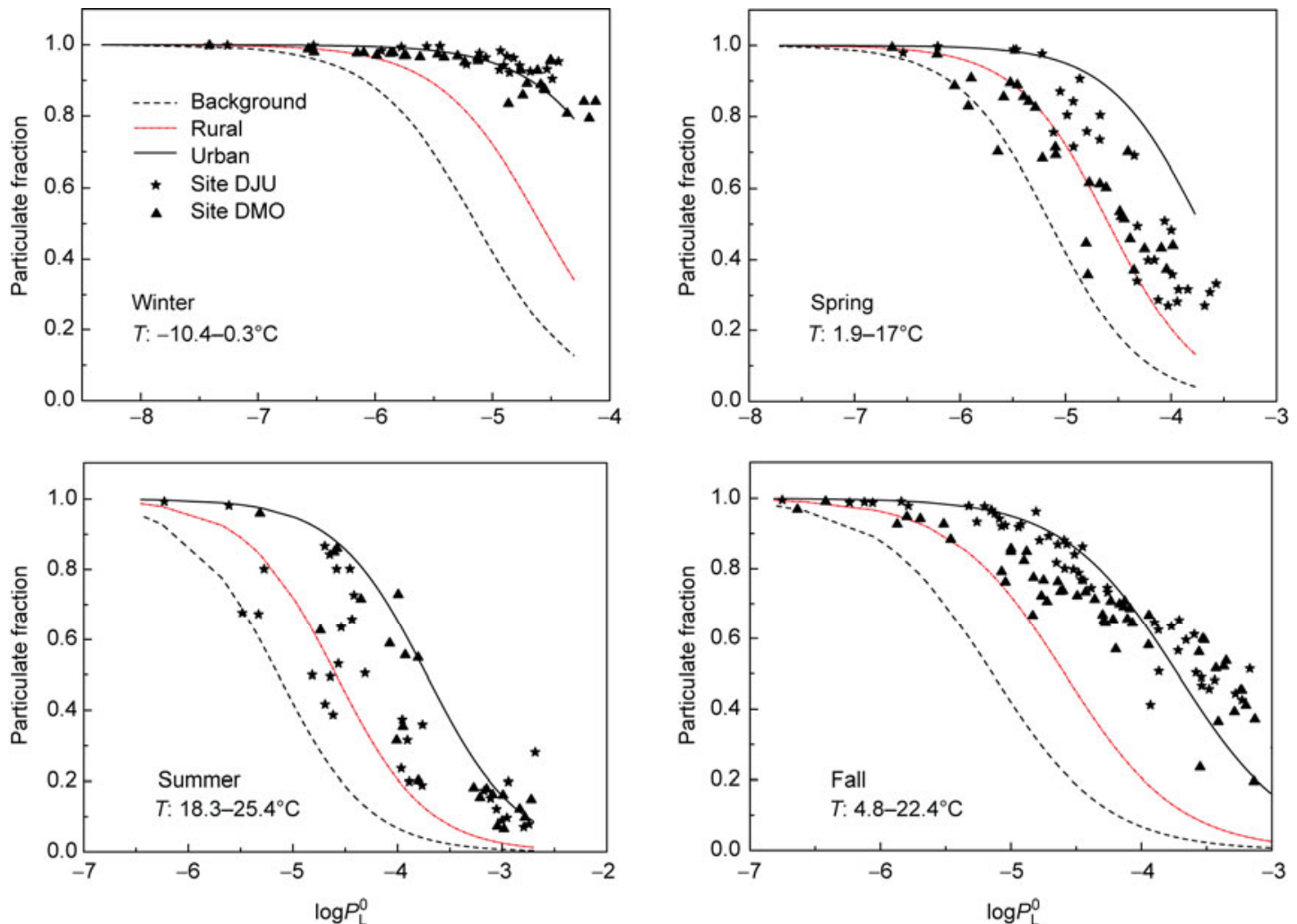

Figure 4 (Color online) Junge-Pankow model with predicted and measured PCDD/Fs distributions.
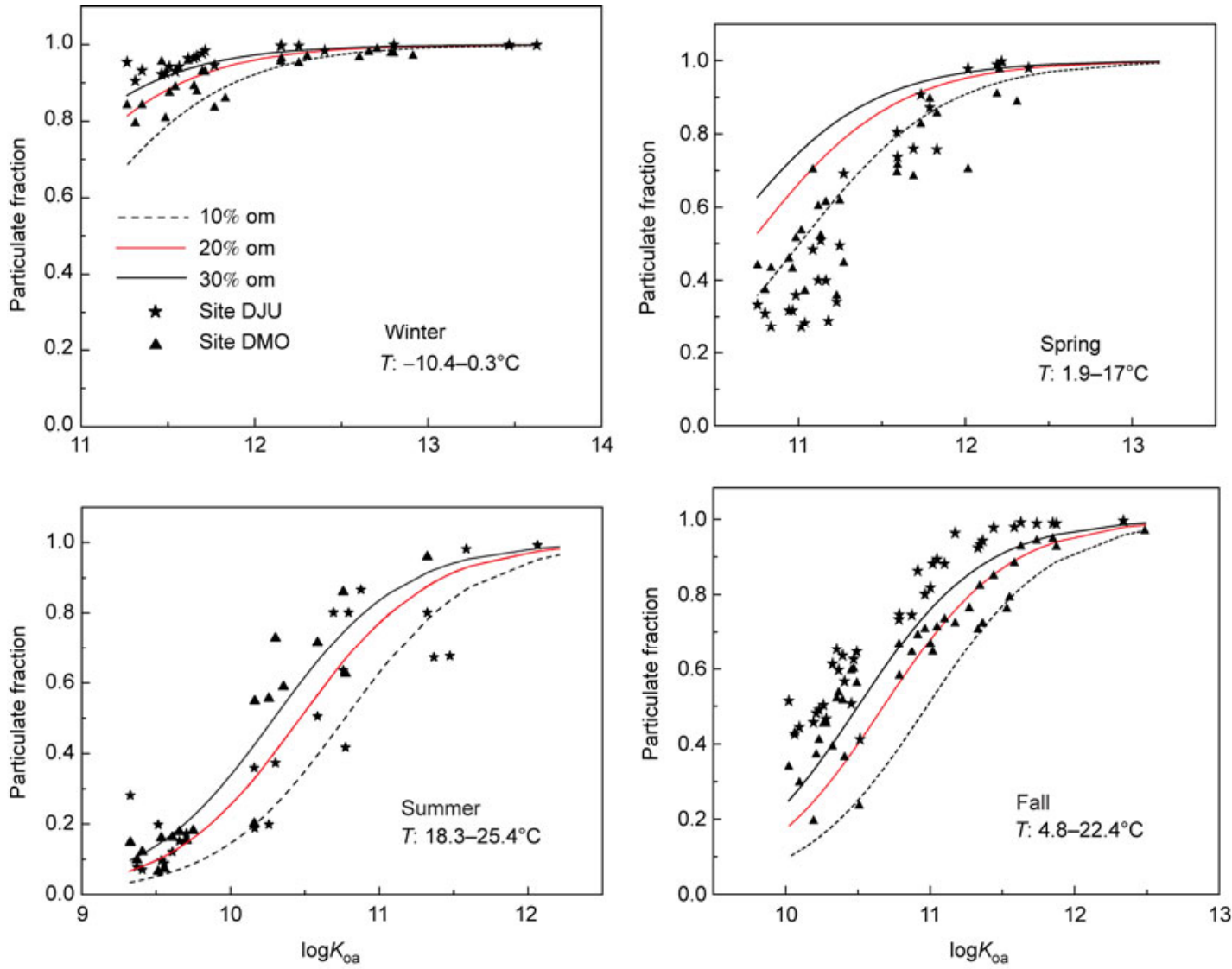

Figure 5 (Color online) The Harner and Bidleman model with predicted and measured PCDD/Fs. 
time indexes (RTI) for dioxins and furans at a single temperature:

$$
\log K_{\mathrm{oa}}=a^{\prime}+b^{\prime}(\mathrm{RTI}),
$$

where $a^{\prime}$ and $b^{\prime}$ are coefficients that are estimated using empirical relationships with temperature. For group 1: $a^{\prime}=$ $1672+T-2.98$ and $b^{\prime}=0.857 / T+7 \times 10^{-5}$; For group 2: $a^{\prime}=$ $986 / T+0.55$ and $b^{\prime}=1.717 / T-0.0032$. Group 1 was defined as any PCDD/Fs not in group 2, and group 2 was defined as any tetra- to hexchlorinated PCDD/Fs having three or four chlorine atoms in the 2,3,7,8 substitution positions. The $T$ in the above formulas for calculating $a^{\prime}$ and $b^{\prime}$ was average ambient temperature in each sampling season, and the unit of which is $K$.

Figure 5 shows that a relative good agreement was obtained between predictions and measured data during winter and summer. Moreover, the observed particle fractions of lower chlorinated compounds at DMO during spring were close to the predicting curves with $10 \%$ organic matter. Although the absorption model underestimated the particle fraction of PCDD/Fs at DJU during autumn, the trends of the predicated and measured curves was similar, and a relative good agreement was obtained between predictions and measured data at DMO during autumn.

From the above results, it can be concluded that JungePankow model was more accurate to predict the gas particle distribution during winter, while the predicted values by Harner and Bidleman model gave agreement with the measured data during winter and summer, relatively.

\section{Conclusions}

The I-TEQ value of the urban air of Dalian was comparable to those in the other urban locations around the world. Higher PCDD/Fs concentrations were observed in winter/autumn and lower levels in summer/spring. The homolog profiles presented higher concentrations of PCDFs compared to PCDDs for all samples. The PCDD/Fs pollution source of the air in Dalian was characteristic for thermal source pollution. During winter, spring and autumn, the $\mathrm{Cl}_{4-8} \mathrm{DD} / \mathrm{Fs}$ appeared to be present mainly in the particle phase, while during summer which were dominantly in gas phase. The ratio of $\mathrm{Cl}_{4-8} \mathrm{DD} / \mathrm{Fs}$ contained in particle phase increased with the increase of chlorinated level. The concentrations of PCDD/Fs in gas phase decreased with the increase of atmospheric pressure, and increased with the increase of temperature, but that in particle phase displayed a reverse trend. Junge-Pankow model was more accurate to predict the gas particle distribution during winter, while the predicted values by Harner and Bidleman model gave agreement with the measured data during winter and summer, relatively. The annual average intake dioxin of the residents around the sampling sites was in the range of WHO standards.
This work was supported by the National Natural Science Foundation of China (20877011), the DAAD (German Academic Exchange Service) Scientific Research Visiting Scholarship, the National High Technology Research and Development Program of China (2011AA060604), the State Key Laboratory of Environmental Chemistry and Ecotoxicology, Research Center for Eco-Environmental Sciences, Chinese Academy of Sciences (KF2009-17), the Key Laboratory of Industrial Ecology and Environmental Engineering, Ministry of Education of China (0802) and the Scientific Research Foundation for the Returned Overseas Chinese Scholars, Ministry of Education of China. We thank Professor Lefeng Zhang who revised the English of the manuscript.

1 Hites R A. Dioxins: An overview and history. Environ Sci Technol, 2011, 45: 16-20

2 Kouimtzis T H, Samara C, Voutsa D, et al. PCDD/Fs and PCBs in air borne particulate matter of the greater Thessaloniki area, N. Greece. Chemosphere, 2002, 47: 193-205

3 Li Y M, Jiang G B, Wang Y W, et al. Concentrations, profiles and gas-particle partitioning of polychlorinated dibenzo- $p$-dioxins and dibenzofurans in the ambient air of Beijing, China. Atmos Environ, 2008, 42: 2037-2047

4 Bidleman T F. Atmospheric processes: Wet and dry deposition of organic compounds controlled by their vapor-particle partitioning. Environ Sci Technol, 1998, 22: 361-367

5 Lohmann R, Harner T, Thomas G O, et al. A comparative study of the gas-particle partitioning of PCDD/Fs, PCBs, and PAHs. Environ Sci Technol, 2000, 34: 4943-4951

6 Oh J E, Choi J S, Chang Y S. Gas/particle partitioning of polychlorinated dibenzo- $p$-dioxins and dibenfurans in atmosphere, evaluation of predicting models. Atmos Environ, 2001, 35: 4125-4134

7 Junge C E. Basic consideration about trace constituents in the atmosphere as related to the fate of global pollutants. In: Suffet I H, ed. Fate of Pollutants in the Air and Water Environments. Part I. New York: Wiley-Interscience, 1977. 7-26

8 Pankow J F. Review and comparative analysis of the theories on partitioning between the gas and aerosol particulate phases in the atmosphere. Atmos Environ, 1987, 21: 2275-2283

9 Harner T, Bidleman T F. Octanol-air partition coefficient for describing particle/gas partitioning of aromatic compounds in urban air. Environ Sci Technol, 1998, 32: 1494-1502

10 Pankow J F, Bidleman T F. Effects of temperature, TSP and per cent non-exchangeable material in determining the gas-particle partitioning of organic compounds. Atmos Environ, 1991, 25: 2241-2249

11 Goss K W, Schwarzenbach R P. Gas/solid and gas/liquid partitioning of organic compounds: Critical evaluation of the interpretation of equilibrium constants. Environ Sci Technol, 1998, 32: 2025-2032

$12 \mathrm{Wu} \mathrm{W} \mathrm{Z,} \mathrm{Schramm} \mathrm{K} \mathrm{W,} \mathrm{Xu} \mathrm{Y,} \mathrm{et} \mathrm{al.} \mathrm{Mobility} \mathrm{and} \mathrm{profiles} \mathrm{of} \mathrm{poly-}$ chlorinated dibenzo- $p$-dioxins and dibenzoforans in sediment of Ya-Er lake area, China. Water Res, 2001, 35: 3025-3033

$13 \mathrm{Wu} \mathrm{W} \mathrm{Z,} \mathrm{Schramm} \mathrm{K} \mathrm{W,} \mathrm{Xu} \mathrm{Y,} \mathrm{et} \mathrm{al.} \mathrm{Persistence} \mathrm{of} \mathrm{polychlorinated}$ dibenzo-p-dioxins and dibenzoforans (PCDD/F) in Ya-Er lake area, China. Environ Int, 2001, 26: 323-326

$14 \mathrm{Wu} \mathrm{W} \mathrm{Z,} \mathrm{Schramm} \mathrm{K} \mathrm{W,} \mathrm{Xu} \mathrm{Y,} \mathrm{et} \mathrm{al.} \mathrm{Contamination} \mathrm{and} \mathrm{distribution}$ of polychlorinated dibenzo- $p$-dioxins and dibenzoforans $(\mathrm{PCDD} / \mathrm{F})$ in agriculture fields in Ya-Er lake area, China. Ecotox Environ Safe, 2002, 53: 141-147

15 Zhang M H, Bao Z C, Yang $\mathrm{H}$, et al. Polychlorinated dibenzo- $p$-dioxins and dibenzoforans in lake sediments from Chinese schistosomiass areas. Bull Environ Contam Toxicol, 1997, 59: 653-656

16 Zhang M H, Bao Z C, Zhang B, et al. Polychlorinated dibenzo-p-dioxins and dibenzoforans in paper making from a pulp mill in China. Chemosphere, 22001, 44: 1335-1337

17 Chen J W, Zhao H M, Gao L N, et al. Atmospheric PCDD/F and PCB levels implicated by pine (Cedrus deodara) needles at Dalian, China. Environ Pollut, 2006, 144: 510-515

18 Yu L P, Mai B X, Meng X Z, et al. Particle-bound polychlorinated dibenzo- $p$-dioxins and dibenzofurans in the atmosphere of Guangzhou, China. Atmos Environ, 2006, 40: 96-108 
19 Li H R, Feng J L, Sheng G Y, et al. The PCDD/F and PBDD/F pollution in the ambient atmosphere of Shanghai, China. Chemosphere, 2008, 70: 576-583

20 Wang W, Qin S, Song Y, et al. Pollution level and distribution of PCDD/PCDF congeners between vapor phase and particulate phase in winter air of Dalian, China. J Environ Sci, 2011, 23(Suppl): 36-39

21 Chang M B, Weng Y M, Lee T Y, et al. Sampling and analysis of ambient dioxins in northern Taiwan. Chemosphere, 2003, 51: 11031110

22 Chao M R, Hu C W, Chen Y L, et al. Approaching gas-particle partitioning equilibrium of atmospheric PCDD/Fs with increasing distance from an incinerator: Measurements and observations on modeling. Atmos Environ, 2004, 38: 1501-1510

23 Mader B T, Pankow J F. Vapor pressures of the polychlorinated dibenzodioxins (PCDDs) and the polychlorinated dibenzofurans (PCDFs). Atmos Environ, 2003, 37: 3103-3114

24 Xu M X, Yan J H, Lu S Y, et al. Gas/particle partitioning of atmospheric PCDD/Fs in a satellite town in Eastern China. Chemosphere, 2009, 76: 1540-1549

25 Lohmann R, Green N J L, Jones K C. Atmospheric transport of polychlorinated dibenzo- $p$-dioxins and dibenzofurans (PCDD/Fs) in air mass across the United Kingdom and Ireland: Evidence of emissions and depletion. Environ Sci Technol, 1999, 33: 2872-2878

26 Lee R G, Green N J, Lohmann R, et al. Seasonal, anthropogenic, air mass, and meteorological influences on the atmospheric concentrations of polychlorinated dibenzo- $p$-dioxins and dibenzofurans (PCDD/Fs): Evidence for the importance of diffuse combustion sources. Environ Sci Technol, 1999, 33: 2864-2871

27 Liu G Y, Chen Z S, Shi Y H, et al. PCDD/Fs in Beijing atmospheric deposition samples (in Chinese). Environ Chem, 2007, 26: 684-688

28 Niu J F, Chen J W, Henkelmann B, et al. Photodegradation of PCDD/Fs absorbed on spruce (Picea abies (L) Karst.) needles under sunlight irradiation. Chemosphere, 2003, 50: 1217-1225

29 Correa O, Rifai H, Raun L, et al. Concentrations and vapor-particle partitioning of polychlorinated dibenzo- $p$-dioxins and dibenzofurans in ambient air of Houston, TX. Atmos Environ, 2004, 38: 6687-6699

30 Luthard P, Mayer J, Fuchs J. Total TEO emissions (PCDD/F and PCB) from industrial sources. Organohalogen Compds, 2000, 45: 344-347

31 Lohmann R, Lee R G, Green N J, et al. Gas-particle partitioning of PCDD/Fs in daily air samples. Atmos Environ, 2000, 34: 2529-2537

32 Lee S J, Park H, Choi S D, et al. Assessment of variations in atmospheric PCDD/Fs by Asian dust in Southeastern Korea. Atmos Environ, 2007, 41: 5876-5886

33 Yamasaki H, Kuwata K, Miyamoto H. Effects of ambient temperature on aspects of airborne polycyclic aromatic hydrocarbons. Environ Sci Technol, 1982, 16: 189-194

34 Pankow J F. An absorption model of gas/particle partitioning of organic compounds in the atmosphere. Atmos Environ, 1994, 28: 185188

35 Simick M F, Franz T P, Zhang H X, et al. Gas-particle partitioning of PCBs and PAHs in the Chicago urban and adjacent coastal atmosphere: States of equilibrium. Environ Sci Technol, 1998, 32: 251-257

36 Nouwen J, Cornelis C, Wevers M, et al. Health risk assessment of dioxin emissions from municipal waste incinerators: The Neerlandquarter (Wilrijk, Beigium). Chemosphere, 2001, 43: 909-923

37 Yu L P. Preliminary study on levels of PCDD/Fs in atmosphere of Guangzhou and typical emission sources of PCDD/Fs, China. Doctor Dissertation. Guangzhou: Graduate School of the Chinese Academy of Sciences, 2007. 42-43

38 WHO European Centre for Environment and Health, International Programme on Chemical Safety. Assessment of the health risk of dioxins: Re-evaluation of the Tolerable Daily Intake (TDI). Geneva, Switzerland, 1998

39 Finizio A, Mackay D, Bidleman T F, et al. Octanol-air partitioning coefficients as a predictor of partitioning of semi-volatile organic chemicals to aerosols. Atmos Environ, 1997, 31: 2289-2296

40 Harner T, Green N J L, Jones K C. Measurements of octanol-air partition coefficients for PCDD/Fs: A tool in assessing air-soil equilibrium status. Environ Sci Technol, 2000, 34: 3109-3114

Open Access This article is distributed under the terms of the Creative Commons Attribution License which permits any use, distribution, and reproduction in any medium, provided the original author(s) and source are credited.

\section{Supporting Information}

Table S1 The concentrations ( $\mathrm{fg} \mathrm{m}^{-3}$ ), I-TEQs (fg-TEQ $\mathrm{m}^{-3}$ ) values of seventeen most toxic 2,3,7,8-substituted PCDD/Fs, $\sum$ PCDD/Fs and $\sum$ PCDD/ $\sum$ PCDF in the air of Dalian

Table S2 Comparison I-TEQ $\left(\mathrm{fg} \mathrm{m}^{-3}\right)$ value of PCDD/Fs in the air of Dalian with the other urban locations around the world

Table S3 Spearman rank correlation coefficients of the concentrations of $\mathrm{Cl}_{4-8} \mathrm{DD} / \mathrm{Fs}$ with meteorological parameters

The supporting information is available online at csb.scichina.com and www.springerlink.com. The supporting materials are published as submitted, without typesetting or editing. The responsibility for scientific accuracy and content remains entirely with the authors. 